\title{
CRB (CURSO REALIDADE BRASILEIRA) NO PIAUÍ: DARCY RIBEIRO E O POVO BRASILEIRO - UM LIVRO MANIFESTO
}

\section{CRB (BRAZILIAN REALITY COURSE) IN PIAUÍ: DARCY RIBEIRO AND THE BRAZILIAN PEOPLE - A MANIFEST BOOK}

Iael de Souza ${ }^{1}$

\section{RESUMO}

CRB (Curso Realidade Brasileira) no Piauí: Darcy Ribeiro e O Povo Brasileiro - um livro Manifesto: Darcy Ribeiro é uma figura controversa. Sua atuação, durante sua trajetória de vida, é polêmica. Porém, apesar dos pesares, a obra O Povo Brasileiro apresenta contribuições relevantes e atuais para o contexto e conjuntura histórico-social presentes. E são delas que nos ocuparemos. O artigo as enfatiza e destaca, demonstrando sua importância no processo de (re)construção de um projeto político-social de cunho popular, de alma social, demonstrando as condições essenciais, segundo Darcy Ribeiro, para a passagem da "classe em si” para a "classe para si", indo além dos interesses e necessidades de sua classe, visando os do gênero humano.

PALAVRAS-CHAVE: Cunhadismo - Transfiguração Étnica - Povo-Massa - Povo-Nação.

\begin{abstract}
BRC (Brazilian Reality Course) in Piaui: Darcy Ribeiro and the Brazilian People - a Manifest Book: Darcy Ribeiro is a controversial character. His conduct, throughout his life, is polemical. However, despite all, the title "O Povo Brasileiro" presents relevant and up-dodate contributions to the current historical-social context and conjuncture. Those which are going to be approached. The paper emphasizes and highlights them, demonstrating their importance on the (re)construction process of a social-hearted, masses-oriented politicalsocial project, demonstrating the essential conditions, according to Darcy Ribeiro, for the transition from "class itself" to "class for itself", getting past their class's interests and needs, in order to meet humankind's.
\end{abstract}

KEYWORDS: Cunhadismo - EthnicTtransfiguration - Masses-People - Nation-People. 


\section{INTRODUÇÃO}

No último final de semana de agosto de 2012, foi inaugurado, nas dependências do campus de Picos, da Universidade Federal do Piauí, o Curso Realidade Brasileira, nascido da percepção da necessidade de se retomar a formação de quadros/militantes de forma mais sistemática, e (re)pensar o Brasil e um Projeto Político-Social Popular alternativo e contrahegemônico ao capital e à sociabilidade capitalista.

Esse curso já foi realizado em vários estados do Brasil, mas é inédito no estado do Piauí. Com mais de 12 anos de existência, sua finalidade é contribuir para a formação político-social das lideranças dos movimentos sociais atuantes no território brasileiro, possibilitando uma apropriação histórico-social contextualizada da realidade e de suas contradições, construída mediante um embasamento teórico crítico-reflexivo para uma práxis lúcida, de ações e consequências mais efetivas, a curto, médio e longo prazo.

No Piauí, o curso foi pensado e articulado pelos seguintes movimentos: a) MPA (Movimento dos Pequenos Agricultores); b) Consulta Popular; c) Levante Popular da Juventude e d) RECID (Rede de Educação Cidadã), que estabeleceram uma parceria com a Universidade Federal do Piauí, campus de Picos, sendo elaborado como um projeto de extensão dessa universidade, através do departamento de Pedagogia.

Devido à experiência acumulada ao longo dos anos, os movimentos sociais são unânimes em reconhecer a importância do CRB (Curso Realidade Brasileira) no tocante a mobilização, organização e formação político-social dos quadros, militantes e lideranças dos movimentos e organizações sociais, populares.

O CRB-PI (Curso Realidade Brasileira, Piauí) será desenvolvido em oito etapas, tendo iniciado em agosto de 2012, com término previsto para abril de 2013. O primeiro módulo retoma a obra de Darcy Ribeiro, O Povo Brasileiro, recontextualizando sua importância e relevância na atualidade, na medida em que traz contribuições inegáveis para se pensar a construção de um projeto político-social popular contra-hegemônico e alternativo ao capital e à lógica da desordem ordenada da sociabilidade capitalista.

O presente artigo elenca algumas dessas contribuições essenciais, demonstrando sua capacidade em despertar as lideranças, quadros e militantes dos movimentos sociais para a necessidade inquestionável, imprescindível e ineliminável da fundamentação teórica para uma ação lúcida e consequente, pois como assevera Ivo Tonet, com o qual concordamos, "o conhecimento, o mais adequado possível do objeto, é condição essencial para a sua 
transformação. E como o objeto é uma unidade de essência e aparência, impõe-se o trabalho e áspero caminho da ciência para desvendá-lo" (TONET, 1998, p. 13).

\section{DARCY RIBEIRO E O CONTEXTO HISTÓRICO-SOCIAL DE SEU TEMPO}

Como alerta o historiador Phillipe Lévillan (2003), as trajetórias de vida, a biografia de um determinado indivíduo social, auxilia-nos a compreender as motivações que orientam e conduzem as ações desse mesmo indivíduo, evidenciando as circunstâncias e condições histórico-sociais que lhe servem de pano de fundo, estabelecendo as complexas relações mediativas entre passado e presente, memória e projeto, indivíduo e sociedade, expondo as contradições das situações vividas ao longo do percurso, que podem explicar as continuidades e descontinuidades, ou as continuidades nas descontinuidades, bem como as descontinuidades nas continuidades, dos modos de ser, agir e pensar.

Darcy Ribeiro nasce em 26 de outubro de 1922, cem anos após a proclamação da falsa e alardeada independência do Brasil, em 1822. Em 1889 uma nova mudança no regime político acontecia, instaurando a República que, no imaginário social, era sinônimo de esperança de tempos e qualidade de vida melhores, sendo que as duas últimas décadas do século XIX marcaram a intensificação do processo de urbanização e do crescimento industrial brasileiro, aprofundando os problemas, as tensões e conflitos sociais pelo crescente descontentamento das camadas populares com suas condições de vida e trabalho, e da classe industrial incipiente com a ausência de um projeto de desenvolvimento econômico-social interno, voltado a atender os interesses endógenos, mais precisamente, seus interesses de classe.

A insatisfação com o cenário político-econômico-social brasileiro é crescente, tanto do lado da classe trabalhadora como do da proprietária dos bens e meios de produção. O regime republicano não havia trazido melhorias nas condições de vida e trabalho das camadas populares e também não atendia aos reclames de participação política da classe comercial e industrial emergentes. Do lado dos populares, aspirava-se a uma proposta de desenvolvimento econômico-social nacional e popular. Por sua vez, do lado da classe comercial e industrial, ansiava-se por um projeto de desenvolvimento econômico-social liberal e conservador, ou seja, realizar as mudanças necessárias para a rearticulação das relações de força e poder entre as classes proprietárias, colocando os latifundiários em seu devido lugar, de modo a conservar 
e manter, para a totalidade dos proprietários, a estrutural social desigual, alicerçada na produção social e na apropriação privada da riqueza social.

Assim, de 1889 a 1930, conflitaram dois projetos de desenvolvimento econômicosocial para o Brasil e as tensões entre a classe proprietária e a classe não-proprietária (os trabalhadores, de modo geral, seja sob regime servil, escravo ou assalariado) agudizaram-se ainda mais devido ao surgimento do proletariado nas cidades, fruto do desenvolvimento urbano-industrial, marcando o início da mobilização e organização do movimento operário brasileiro, que veio acentuar-se pela contribuição da entrada dos trabalhadores imigrantes, cujo número chegou a 4.826.394, de 1819 a 1939, conforme Pilete (1996). Os imigrantes traziam a experiência da vivência da industrialização europeia, aprendida pelos confrontos e embates entre capital e trabalho, sendo forte a influência das ideias anarquistas proudonianas, que evidenciaram a irremediabilidade e irreconciabilidade entre os interesses e necessidades da classe trabalhadora e da classe capitalista.

Muitos anos mais tarde, o próprio Darcy Ribeiro diria, em O Povo Brasileiro (1995), que a única saída possível do impasse entre exploradores e explorados, a única forma de superar a estrutura social autoperpetuante de opressão e exploração, era o surgimento e expansão do movimento operário. Segundo suas palavras:

nas cidades, ao contrário da roça, o operário sindicalizado já atua como um lutador livre diante do patrão, chegando a ser arrogante na apresentação de suas reivindicações. É por esse caminho que as instituições políticas podem aperfeiçoarse, dando realidade funcional a República. (RIBEIRO, 1995, p. 219)

O ano de nascimento de Darcy Ribeiro, 1922, é considerado um divisor de águas entre o antigo e o moderno na cultura brasileira, correspondendo ao Modernismo, movimento que representa o triunfo da razão, da ciência e da tecnologia, características marcantes da civilização industrial, moderna. A instabilidade e a fragmentação são sua tradução. Como asseverado por Marx, no modo de produção capitalista, tudo o que é sólido se desmancha no ar.

O arrefecer dos ânimos, o clima de insatisfação e o perigo eminente de uma revolução social, animada pelo acontecimento histórico-social da Revolução Russa, de 1917, prepara o golpe da dita "Revolução de 1930", onde a classe proprietária se une, suspendendo momentaneamente suas diferenças, para garantir a manutenção do status quo, da ordem para o progresso, e da perpetuação da estrutura e estratificação social de classes. O projeto de 
desenvolvimento econômico-social nacional-popular era frustrado mais uma vez, e se poria em marcha aquele outro projeto, de caráter liberal-conservador.

Porém, a "Revolução de 1930" não demora a ser desmascarada como revolução pelo alto e de rearticulação do poder entre as elites proprietárias, e o movimento operário e a sociedade civil pressionam por mudanças que atendam suas reivindicações de participação política e social efetivas nos rumos do país. A ditadura do Estado-Novo, de 1937 a 1945, é a resposta do aparato jurídico-político estatal, procurando garantir, mais uma vez, a ordem para o progresso, acelerando a criação das condições infraestruturais para o processo de modernização e industrialização do Brasil.

Em 1946, então com 24 anos, Darcy Ribeiro forma-se em antropologia pela Escola de Sociologia e Política de São Paulo, que agregava a nata da intelectualidade crítica da época. O fim da ditadura Vargas permitiu que as forças reprimidas e contidas de amplos setores da sociedade brasileira aflorascem, resultando numa ampla mobilização das massas, liderada pelo conjunto de forças político-ideológicas que almejavam um projeto de desenvolvimento econômico nacional e popular.

Esse panorama conjuntural também produziu um rearranjo sintomático e significativo no pensamento social brasileiro, e nas décadas de 1950 e 1970, como enfatiza Adelia Ribeiro, "ganhou visibilidade uma geração de intelectuais emblemáticos no empenho de construção e defesa de uma sociedade democrática e moderna que, nem por isso, aderisse acriticamente a modelos importados" (MIGLIEVICH-RIBEIRO, 2011, p. 27). A criação da CEPAL (Comissão Econômica para a América Latina), em 1948, é um dos sintomas dessa mudança, preocupada em passar a limpo a nossa história, analisar, compreender e reestruturar o desenvolvimento brasileiro através de um projeto de desenvolvimento político-econômico que privilegiasse os interesses e necessidades endógenos e não os exógenos, como havia sido ao longo da formação socioeconômica e cultural do Brasil.

Também é importante lembrarmos que de 1939 a 1945 o mundo vivenciou a drástica experiência de uma segunda Guerra Mundial, que marcou a ascensão da indústria armamentícia, nuclear e das inovações científico-tecnológicas que, a partir de 1950, seriam responsáveis pela revolução nas comunicações, produzindo o surgimento da denominada "sociedade informacional e do conhecimento", que significa, na verdade, a possibilidade de transnacionalização e financeirização da economia capitalista de mercado, inaugurando a era do império do capital, maquiada, de modo ideologizado, pelo conceito de globalização, que na década de 1980 mostraria sua verdadeira face através da mundialização da reestruturação produtiva e sua consequência imediata, o desemprego estrutural, e do projeto político- 
econômico neoliberal de desregulamentação trabalhista, fiscal, produtiva, pela precarização das condições de vida da classe trabalhadora em escala planetária e pelo processo de privatização do público-estatal, como demonstrado por Anderson (1998).

O contexto do pós-45 é denominado de Pós-Modernismo, onde o real cede lugar ao símbolo e ao signo, como demonstra Peter McLaren (2003), já que as questões da mediação são substituídas pelas da representação. É o mundo da sociedade do espetáculo, onde o consumo é a condição para a realização da felicidade dos indivíduos sociais, padronizando e uniformizando as maneiras de ser, sentir, viver e pensar, alterando a noção de temporalidade, já que não mais importa a média e longa duração, apenas a curta, porque na sociedade consumista o que vale é a pulsão dos desejos e a sua satisfação imediata, tornando os indivíduos cada vez mais individualistas, hedonistas, egocêntricos, imediatistas, superficiais e descartáveis, assim como as relações humanas, cada vez mais desumanizadas.

Em O Povo Brasileiro (1995), Darcy Ribeiro faz menção a esse contexto históricosocial ao tratar sobre a questão da deterioração urbana, onde diz que as:

\begin{abstract}
instituições tradicionais estão perdendo todo o seu poder de controle e doutrinação. A escola não ensina, a igreja não catequisa, os partidos não politizam. O que opera é um monstruoso sistema de comunicação de massa fazendo a cabeça das pessoas. Impondo-lhes padrões de consumo inatingíveis, desejabilidades inalcançáveis, aprofundando mais a marginalidade dessas populações e seu pendor a violência. Algo tem que ver a violência desencadeada nas ruas com o abandono dessa população entregue ao bombardeio de um rádio e de uma televisão social e moralmente irresponsáveis, para as quais é bom o que mais vende, refrigerantes ou sabonetes, sem se preocupar com o desarranjo mental e moral que provocam (RIBEIRO, 1995, p. 207)
\end{abstract}

Darcy Ribeiro é influenciado por todo esse contexto e conjuntura político-econômicohistórico-social. De 1946 a 1954 colocará em prática os conhecimentos acumulados e sistematizados ao longo de sua formação acadêmica, realizando estudos antropológicos junto aos índios do Pantanal, do Brasil Central e da Amazônia. Acreditava que a vocação da antropologia era a competência para "elaborar uma teoria sobre o humano e sobre as variantes do humano e melhorar o discurso dos homens sobre os homens", conforme rememora Adelia Ribeiro (MIGLIEVICH-RIBEIRO, 2011, p. 28), contribuindo para o processo de autoconhecimento e autoconstrução humana e de sua identidade enquanto ser humano. Porém, os estudos com os povos indígenas exerceu uma contribuição indubitável e fecunda sobre a compreensão da especificidade da formação do povo brasileiro, como veremos mais a frente. 
A atuação e engajamento de Darcy Ribeiro na política ganhou expressão na década de 1950. Comungava as preocupações dos cepalinos no tocante a criação das condições capazes de possibilitar a construção de um projeto de desenvolvimento nacional popular para o Brasil. A oportunidade de atuar nessa direção ocorreu durante o tumultuado governo de João Goulart (1961-1964), exercendo o cargo de Chefe da Casa Civil. Um período de crise econômica e agitação social-popular, marcada por greves e levantes na cidade e no campo, que pressionava pelas reformas estruturais no país, as reformas de base. Novamente, o perigo eminente de uma revolução social se avizinhava e, mais uma vez, a manutenção da ordem foi assegurada através do golpe militar de 1964, momento em que Darcy Ribeiro, fugindo da perseguição dos militares, exila-se por um período de 12 anos, de 1964 a 1976, quando retornará ao Brasil.

É importante registrarmos que foi em meados da década de 1950 que Darcy Ribeiro empreendeu a primeira tentativa de escrever o livro O Povo Brasileiro, entendida por ele como véspera de uma revolução social transformadora. Contudo, era um homem de "fazimentos", como se autodenominava, e viu-se envolvido em outras tantas atividades que o impediram de prosseguir na escrita.

Foi justamente no exílio, durante sua permanência no Uruguai, embora tenha vivido em alguns outros países da América Latina, como Chile e Peru, que produziu a primeira versão do livro, depois de dois anos de trabalho, resultando em quatrocentas páginas densas. Interessante a conclusão que o próprio Darcy Ribeiro chegou após a leitura crítica da obra. Diz que levou um susto ao constatar que "não dizia nada, ou pouco dizia que não tivesse sido dito antes. O pior é que não respondia às questões que propunha, resumíveis na frase que, desde então, (passou) a repetir: por que o Brasil não deu certo?” (RIBEIRO, 1995, p. 13)

A fim de responder a esse pergunta nodal, Darcy Ribeiro, ainda no exílio, inicia uma série de estudos que resultaram em cinco volumes, intitulados Estudos de Antropologia da Civilização. Dizia-se herdeiro de Marx e Engels, incumbido da tarefa de explicar as especificidades e particularidades da formação socioeconômica brasileira à luz das condições e circunstâncias histórico-sociais que lhes são próprias. É assim que empreende a (re)construção de uma teoria geral da história para desvelar as particularidades e especificidades da formação e sentido do Brasil, porque as teorias existentes eram demasiadamente eurocêntricas, logo, "impotentes para nos fazer inteligíveis" (RIBEIRO, 1995, p. 13).

É interessante transcrevermos, aqui, os objetivos a serem atingidos em cada estudo, enfatizando, mais uma vez, o fio condutor que guiará Darcy Ribeiro durante todo o percurso planejado, que é responder o por que o Brasil não deu certo. O primeiro desses estudos é a) $O$ 
Processo Civilizatório, de 1968, resultando na construção de uma teoria da história que situasse o Brasil na história humana. Segundo Darcy Ribeiro, "um esquema conceitual mais verossímel e mais explicativo do que os disponíveis, através da proposição de novas revoluções tecnológicas como motores da história, de novos processos civilizatórios e de novas formações socioculturais" (RIBEIRO, 1995, p. 14). Na sequência compõe b) As Américas e a Civilização, de 1970, onde procura reconstituir o processo de formação dos povos americanos, "num esforço para explicar as causas do seu desenvolvimento desigual" (RIBEIRO, 1995, p. 15).

Através desses dois estudos preliminares, Darcy Ribeiro nos fazia inteligíveis, mas a questão essencial que se propusera ainda não havia sido respondida e permanecia: por que, afinal, o Brasil não deu certo? No intuito de encontrar a resposta, escreve c) Os Dilemas da América Latina, de 1971, realizando uma radiografia dos esquemas das classes sociais, construindo uma tipologia das formas de exercício do poder e de militância política, produzindo, de acordo com suas palavras, "uma teoria de base empírica das classes sociais, tais como elas se apresentam no nosso mundo brasileiro e latino-americano" (RIBEIRO, 1995, p. 16). Depois, escreve d) Os Brasileiros: Teoria do Brasil, de 1972, uma concatenação dos outros três livros, trazendo de novidade a teoria da cultura, demonstrando que "o saber erudito é tantas vezes espúrio e o não-saber popular alcança, contrastantemente, altitudes críticas, mobilizando consciências para movimentos profundos de reordenação social." (RIBEIRO, 1995, p. 16) Aqui, Darcy Ribeiro enfatiza e congratula a criatividade popular, já que "mescla as tradições mais díspares, o que nos permite compreender essa nossa nova versão do mundo e de nós mesmos" (RIBEIRO, 1995, p. 16).

Encerrando os volumes, em 1975 escreve e) Os Índios e a Civilização, onde cunha o conceito de transfiguração étnica, ou seja, “o processo através do qual os povos surgem, se transformam ou morrem" (RIBEIRO, 1995, p. 16 e 17). O livro O Povo Brasileiro, publicado em 1995, é a nova síntese resultante das interdeterminações e imbricações dialéticas dos Estudos de Antropologia da Civilização. É lícito destacarmos a ressalva feita pelo próprio autor em relação ao livro, rebatendo algumas das inúmeras críticas realizadas por seus pares da academia, extremamente acadêmicos - regidos pelo método de produção científica positivista - e muito pouco militantes. Nas palavras de Darcy Ribeiro, esse livro, "além de um texto antropológico, é, e quer ser, um gesto meu na nova luta por um Brasil decente" (RIBEIRO, 1995, p. 17). Trata-se, portanto, de um livro manifesto, e não uma obra científica nos moldes e termos positivistas tradicionalmente legitimados pelo cientificismo academicista. Para que não paire nenhuma dúvida, o autor complementa: 
Não se iluda comigo (...). Além de antropólogo, sou um homem de fé e de partido. Faço política e faço ciência movido por razões éticas e por um fundo patriotismo. Não procure, aqui, análises isentas. Este é um livro que quer ser participante, que aspira a influir sobre as pessoas, que aspira a ajudar o Brasil a encontrar-se a si mesmo. (RIBEIRO, 1995, p.17)

O retorno ao Brasil, em 1976 - que sofre com as consequências da crise do modelo fordista e do capitalismo mundial de 1970 -; a anistia, em 1980 e sua filiação ao PTB (Partido Trabalhista Brasileiro), voltando a dedicar-se à educação e à política, atuando nos dois governos de Brizola no Rio de Janeiro, de 1983-1987 e de 1991-1994, como Secretário de Estado da Cultura, criando os CIEP's (Centros Integrados de Educação Pública), referência para a rede pública em termos de estrutura e proposta político-pedagógica, funcionando em horário integral, voltados para o atendimento de crianças e adolescentes, são alguns de seus fazimentos e militância.

A década de 1980 corresponde ao processo de reabertura democrática, gradativamente iniciada na segunda metade da década de 1970. A CUT (Central Única dos Trabalhadores) é fundada em meados da década de 1980 e os movimentos sociais e populares perseguidos e caçados durante o período ditatorial retornam à legalidade, resistindo e se opondo as orientações político-econômicas neoliberais. Como afirma Frigotto (2005, p.237),

ao longo do século XX, entre ditaduras e golpes de diferentes tipos, foram sendo construídos, por forças críticas ao capitalismo (anarquistas, socialistas e comunistas) ou liberais sociais, espaços de avanço na construção de propostas de projetos alternativos de sociedade e de educação. Os anos de 1980, após uma ditadura de duas décadas, processaram uma espécie de síntese desse acúmulo e aprendizado histórico.

É assim que uma ampla mobilização dos movimentos sociais, sindicalismo classista e partidos com uma proposta ideológica alternativa ao capitalismo teve larga influência no debate constituinte, culminando com a pressão sobre os parlamentares para o atendimento das reivindicações dos movimentos sociais e populares, arrancando e conquistando as concessões que aparecem na Constituição de 1988, que será paulatinamente minada e adulterada através de emendas, decretos, projetos de lei e medidas provisórias, que se perpetuam, ao longo da década de 1990, até hoje.

Como recorda Cassia Damiani (2004), em 1989, como resultado desse processo de mobilização e organização política-social, forma-se a FBP (Frente Brasil Popular), 
construindo alianças entre vários partidos e forças políticas a esquerda, democratas e progressistas, que deram sustentação à candidatura de Luis Inácio Lula da Silva para presidência da República, em 1989. Novamente, está em disputa dois projetos de nação:

a) projeto internacional e elitista de dominação econômica com princípios neoliberais 'modernizantes', que tinha como objetivo amenizar a crise do capitalismo mundial, representado por Collor de Mello; b) projeto popular, de cunho nacional, com vistas ao desenvolvimento dos setores estratégicos da economia, no fortalecimento e crescimento do país, com tecnologia nacional e de forma independente, com soberania, representado pela FBP. (DAMIANI, 2004, p. 118)

Sabemos qual projeto saiu vitorioso. Primeiro Collor de Melo, de 1989 a 1992, sendo substituído por Itamar Franco, de 1993 a 1994, devido o impeachment, para oito anos de governo de FHC (Fernando Henrique Cardoso), de 1995 a 2002, consolidando e implementando os imperativos categóricos da cartilha neoliberal ditados aos países periféricos por FMI (Fundo Monetário Internacional), BIRD (Banco Interamericano de Desenvolvimento) e Banco Mundial. FHC rompe com a corrente cepalina que integrava e declara na imprensa que a partir do momento do seu primeiro governo, deveríamos esquecer tudo o que havia escrito enquanto membro da CEPAL. A ruptura de FHC com o projeto de desenvolvimento nacional-popular representa um posicionamento na luta de classes e a opção pela lógica de fortalecimento e reestruturação do capital, com implicações políticas e sociais significativas para a vida da população brasileira, principalmente para a classe trabalhadora, cada vez mais precarizada e descartável.

Uma onda de esperança revitalizaria os movimentos sociais e populares no processo eleitoral de 2002, quando Luís Inácio Lula da Silva novamente se candidata a presidência da República, e o PT (Partido dos Trabalhadores) cometeria o mesmo erro histórico dos mencheviques de fazer alianças com Deus e o Diabo para garantir a governabilidade, além de conquistar o apoio das massas marginalizadas e em situação precária de vida através das caravanas que percorrem vários estados brasileiros, rememorando a trajetória de vida de Lula e sua identificação com as camadas populares, extraordinariamente explorada pelo carismático candidato, agora mais experiente em relação ao funcionamento da máquina eleitoral brasileira e muito bem auxiliado no campo do marketing publicitário.

Uma reminiscência efervescente do contexto histórico-social de 1989, com todo o seu significado político-social, povoa euforicamente o imaginário dos movimentos sociais e de toda a classe trabalhadora. Era agora ou nunca! Apostava-se na possibilidade de uma 
reviravolta nas relações de força e poder entre capital e trabalho, colocando no horizonte o tão almejado projeto de desenvolvimento econômico nacional e popular, reconstruindo a nação. Analisando o contexto histórico-social da última década do século XX e início do século XXI, Perry Anderson acabou sendo profético, como demonstra Frigotto ao citá-lo. Conforme a análise empreendida por aquele,

\begin{abstract}
na década de 1990 os governos eleitos por forças de centro-esquerda ou esquerda (Inglaterra, Alemanha, França, Espanha, Portugal, Chile, Peru, entre outros) acabaram completando as reformas da direita. Naquele momento, Anderson advertia que o virtualmente eleito presidente, Luiz Inácio Lula da Silva, corria esse risco, ainda que reconhecesse ser ele oriundo de uma história com base social diversa e que poderia fazer a diferença, sendo uma alternativa singular para o mundo. Apontava, porém, quatro exigências, para ele imprescindíveis, para que isso pudesse ocorrer: 1) não confundir os votos ganhos com o poder que deteria; 2) ter um projeto alternativo claro e um grupo coeso na busca de sua concretização; 3) vincular esse projeto aos movimentos sociais organizados e 4) identificar o inimigo sem subestimá-lo. (ANDERSON apud FRIGOTTO, 2005, p. 241).
\end{abstract}

Infelizmente, nenhuma dessas quatro exigências recebeu a devida importância e atenção, dando continuidade a implantação da política-econômica neoliberal, utilizando os movimentos sociais e seus projetos, como o Fome Zero, então desvirtuados de sua proposta original, para amortecer e remediar a situação de uma imensa maioria de trabalhadores cada vez em condições materiais de existência mais precária e miserável, pois o alívio à pobreza é uma exigência para que o capital possa cumprir sua agenda sem maiores perturbações e ameaças a sua ordem e ao seu progresso.

É assim que entendemos a preocupação central e sempre presente que permeou a vida e a obra final de Darcy Ribeiro, O Povo Brasileiro: a necessária construção de um projeto nacional popular pelo Povo-Nação, como teremos oportunidade de compreender ao longo da exposição, deixando de ser apenas uma promessa para realizar-se de fato, já que ainda somos "um povo, até hoje, em ser, na dura busca de seu destino" (RIBEIRO, 1995, p. 453), pois

o que houve e o que há é uma massa de trabalhadores explorada, humilhada e ofendida por uma minoria dominante, espantosamente eficaz na formulação e manutenção de seu próprio projeto de prosperidade, sempre pronta a esmagar qualquer ameaça de reforma da ordem social vigente. (RIBEIRO, 1995, p. 452)

Darcy Ribeiro é levado pelo câncer, ainda que tenha resistido e lutado devido o imenso prazer que tinha em viver a vida, falecendo em 17 de fevereiro de 1997. O povo 
brasileiro ainda não se realizou como tal, ainda luta por ser, como conclui o autor, e para isso necessita se apropriar e sistematizar sua história vivida, compreendendo a dimensão e significado da sua constituição enquanto povo, (re)construindo sua memória e identidade, a fim de que possa construir com lucidez e de forma consequente, um projeto político-social popular que permita o desabrochar e o desenvolvimento, na plenitude possível, de suas potencialidades e capacidades, satisfazendo, verdadeiramente, suas necessidades para além daquelas que representam as da sua classe, mas sendo capaz de por e defender um projeto que transcenda as classes em luta e defenda os interesses e necessidades para a construção efetiva das condições de realização do gênero humano. São essas contribuições de Darcy Ribeiro que veremos a seguir.

\section{CUNHADISMO COMO CRIATÓRIO DE GENTE - POVO-NOVO: OS NEOBRASILEIROS}

Diferentemente do que contam os livros de história pelos quais fomos ensinados ao longo do nosso processo de escolarização e através dos quais sistematizamos a ideia da nossa constituição e formação enquanto povo, o povoamento do Brasil não se deu, efetivamente, em 1532, com a chegada da expedição colonizadora de Martim Afonso e seu efetivo de quatrocentas pessoas, iniciando o processo de estruturação da organização política do território através do regime de donatarias. Darcy Ribeiro demonstra que os neobrasileiros porque mesmo antes de tomar conhecimento do pau de tinta (o pau-Brasil) "os mapas mais antigos da costa já a registram como brasileira e os filhos da terra foram, também, desde logo, chamados 'brasileiros'. Entretanto, o uso do nome como gentílico, que um povo atribua a si mesmo, só surgiria muito tempo depois" (RIBEIRO, 1995, p. 126 e 127) - foram gestados e plasmados através do cunhadismo. Vejamos.

O cunhadismo compreende o sistema de parentesco indígena através do qual um estranho é integrado à comunidade, passando a fazer parte dela. É assim que os europeus (iberos, franceses, holandeses), ao tomarem uma moça índia como esposa, estabeleciam mil laços que o aparentava com todos os membros do grupo. Desse modo, "o europeu passava a contar com uma multidão de parentes, que podia por a seu serviço, seja para conforto pessoal, seja para a produção de mercadorias" (RIBEIRO, 1995, p. 82). Alguns desses europeus, como o português João Ramalho, chegaram a ter trinta esposas, já que a poligamia era a base das 
relações de parentesco, estruturando os primeiros povoados, que se transformaram nas primeiras vilas.

É assim que se dá, efetivamente, o povoamento do território brasileiro e a formação do povo-novo, os neobrasileiros, ainda sem consciência de si, que passaria por um drástico e duplo processo de rejeição - primeiro, por parte da matriz indígena, que só reconhecia a descendência por parte do sexo masculino, uma vez que o feminino era visto como um "saco em que o macho depositava sua semente". (RIBEIRO, 1995, p. 108) De modo que "quem nasce é o filho do pai, e não da mãe" (RIBEIRO, 1995, p. 108). Depois, por parte da matriz lusitana, europeia, que o trata como "impuro filho da terra, aproveitando bem seu trabalho enquanto menino e rapaz e, depois, o integrava a suas bandeiras, onde muitos deles fizeram carreira" (RIBEIRO, 1995, p. 108), introjetando a opressão do opressor e passando a oprimir seus ancestrais, que também rechaçava e hostilizava - para vir a se construir e constituir como povo brasileiro.

Portanto, como esclarece Darcy Ribeiro, "sem a prática do cunhadismo, era impraticável a criação do Brasil. Com ele se estabelecem criatórios de gente mestiça." (RIBEIRO, 1995, p. 83) Esse foi o fato inédito: a miscigenação, resultando no produto real das nações ibéricas, entendidas pelo autor como fecundadoras de nações germinais, já que

os iberos desembarcavam sempre desabusados, acesos e atentos aos mundos novos, querendo fluí-los, recriá-los, convertê-los e mesclar-se racialmente com eles. Multiplicaram-se, em consequência, prodigiosamente, fecundando ventres nativos e criando novos gêneros humanos. (RIBEIRO, 1995, p. 67)

Conforme Darcy Ribeiro, é deste modo que se dá a formação "de um povo-nação plasmado pela mestiçagem, para ser, entre os povos, e de existir para si mesmo" (RIBEIRO, 1995, p. 68). Portanto, se fizermos as contas, da aportagem de Martim Afonso - que introduz os negros africanos, trazidos como serviçais - e sua comitiva, em 1532, ao processo de miscigenação, desde 1492, somam-se quarenta anos. Não é de admirar que a Coroa lusitana tenha se sentido ameaçada em relação a franca concorrência sobre o controle e domínio do território, apressando-se por (re)povoá-lo através da imposição de sua organização políticajurídica-burocrática, criando as bases para o processo de centralização e unificação política das terras brasileiras, como também para a reprodução da estruturação e estratificação social e de classes.

De acordo com Darcy Ribeiro, por volta de "1570 a dominação portuguesa estava assentada solidamente, com uma população de 30 a 40 mil habitantes, em sua maioria 
mamelucos" (RIBEIRO, 1995, p. 94) ou brasilíndios, isto é, os mestiços gerados pela miscigenação entre os europeus e os indígenas, matrizes formadora do povo-novo, ainda em busca de si, porque um desindío, um deseuropeu e desafricano, não se reconhecendo em nenhuma de suas matrizes originais, imerso por um bom tempo na ninguedade até fazer-se consciente de si e de sua brasilidade. Nas palavras de Darcy Ribeiro, "condenado à pretensão de ser o que não era nem existia: o brasileiro" (RIBEIRO, 1995, p. 128).

Já em 1800 a população atingia o número original, anterior ao genocídio e etnocídio indígena, de cinco milhões de habitantes, com população invertida, como elucida Darcy Ribeiro, já que a maioria era composta por "brancos da terra (mestiços)" (RIBEIRO, 1995, p. 157 e 158), seguida de negros e índios.

Vale ressaltar que nesse processo de fazimento do povo-novo que daria vazão ao povo-brasileiro, foram eivadas mais de um milhão de vidas indígenas, numa hecatombe genocida e etnocida atroz, tendo três grandes causas, que ficaram conhecidas no tempo de Mem de Sá como as três pragas do homem branco:

1) a peste, dizimando as tribos indígenas devido as doenças epidêmicas trazidas e disseminadas pelo contato com os europeus e, mais tarde, com os padres jesuítas das missões, numa verdadeira guerra de extermínio bio-bacteriológica;

2) as guerras, onde os índios eram utilizados como combatentes, expulsando os incômodos invasores franceses e holandeses;

3) a escravização, pois com a decadência do cunhadismo passou-se para a guerra de captura e escravização indígena, intensificada quando da formação das bandeiras (bandeirantismo), onde o brasilíndio-mameluco atuava na linha de frente, impondo e exteriorizando a opressão introjetada que sofria, pois também era exímio desbravador das matas, sabendo se locomover por terra e por água, sobrevivendo na floresta e as suas adversidades.

É assim que entendemos as razões que explicam o fato dos imigrantes terem sido absorvidos, assimilados, abrasileirados, pois o povo brasileiro já tinha sido feito à época de sua chegada, já havia sido étnica, nacional (âmbito jurídico-político-socioeconômico) e culturalmente unificado, de modo que "não tiveram maior relevância na fixação das características da população brasileira e da sua cultura. Quando começaram a chegar em maiores contingentes", principalmente durante a primeira Guerra Mundial e no entre guerras, “a população nacional já era tão maciça numericamente e tão definida do ponto de vista étnico, que pôde iniciar a absorção cultural e racial do imigrante sem grandes alterações no conjunto" (RIBEIRO, 1995, p. 242). 
Assim surge o Brasil, os neobrasileiros e o povo brasileiro, impedido de se realizar, efetivamente, para si, como teremos oportunidade de averiguar, como Povo-Nação, sendo organizado e constituído para ser para os outros, sendo um "proletariado externo". Nas palavras de Darcy Ribeiro, um "povo encarado pela classe dominante como mera força de trabalho, destinada a desgastar-se no esforço produtivo e sem outros direitos que o de comer enquanto trabalha, para refazer suas energias produtivas, e o de reproduzir-se para repor a mão-de-obra gasta”. (RIBEIRO, 1995, p. 212)

\section{TRANSFiguraÇão ÉtNiCA E CUltura POPUlar - PARA ALÉM da ACULTURAÇÃO}

Nesse processo de fazimento do povo brasileiro e do fazer-se Brasil, ocorre a transfiguração étnica, entendida enquanto "processo através do qual os povos, enquanto entidades culturais, nascem, se transformam e morrem" (RIBEIRO, 1995, p. 257), como dito anteriormente. É desta forma que podemos entender a diferença substancial entre transfiguração e aculturação, pois não se trata de um processo linear, de um amadurecer para a civilização, mas de uma transformação compulsória, punitiva - introduzindo o sentimento de culpa e de pecado inexistente nas crenças indígenas; segregando as etnias negras, impedindo a formação de núcleos solidários e inviabilizando a retenção do patrimônio cultural africano -, uma impositura das novas condições e circunstâncias histórico-sociais e conjunturais das quais passa a depender a própria viabilidade de existência.

Porém, toda forma de opressão, todo ato de força repressora, e de exercício de poder físico e espiritual produz, dialeticamente, o seu contrário, ou seja, a resistência do oprimido e subjugado. "O povo configurado resiste à transfiguração, e nessa luta de resistência vai mudando para viabilizar a existência no novo contexto" (RIBEIRO, 1995, p. 257). Nasce, assim, o que se convencionou chamar, por parte do "macho adulto branco sempre no comando" (Caetano Veloso - O Estrangeiro), cultura popular, folclore que, na verdade, traduzem o processo de circularização cultural, como demonstra Carlo Ginzburg (1987), isto é, a (re)apropriação e releitura dos valores ideoculturais dominantes pelos dominados, que os resignificam a partir das suas condições materiais de existência, respondendo a suas necessidades de reprodução social, resguardando suas especificidades ao mesmo tempo que proporciona sua integração na generalidade da cultura brasileira, produzindo a diversidade cultural que integra ao invés de segregar. Nessa transfiguração, transforma-se preservando, 
pois mantêm certas continuidades (especificidades, singularidades) nas descontinuidades da mudança (generalização, cultura brasileira). É assim que, “comprimida pelas imposituras, a cultura brasileira tradicional vai se transfigurando, e ante o que é considerado moderno, sobrevive como arcaica" (RIBEIRO, 1995, p. 265).

Compreende-se, assim, porque o povo brasileiro nasce do processo de transfiguração étnica de suas matrizes formadoras: a índia, a europeia e a negra. Das três raças, como menciona repetidamente Darcy Ribeiro. Embora o termo seja polêmico e marcado, ao longo de sua evolução histórica, de preconceitos etnocentristas, como demonstram Santos et. al. (2011), devemos entendê-lo no seu sentido físico-biológico de classificação das espécies no âmbito das ciências naturais, onde os hominídios são conhecidos como espécie humana. A classificação por raças objetiva a diferenciação morfológica e fenotípica (estatura, cor de olhos, formato do rosto e do nariz, tamanho do crânio, cor e tipo de cabelos, cor de pele, etc..) entre a espécie, sendo seu uso defendido na área de saúde "como um meio útil de aprimoramento de diagnóstico e de esforços terapêuticos" (SANTOS, et. al., 2011, p. 121.). Na Ortodontia, por exemplo, "a tentativa de identificar o grupo racial em uma amostra tenta controlar a variação inerente às características faciais específicas a determinados grupos raciais". (SANTOS, et. al., 2009, p. 121).

Todavia, independente da sua aceitação ou não, o termo raça e os atos de racização existem, é um fenômeno socioeconômico e político, perpassado pelas relações de poder e dominação estruturais das e nas sociedades capitalistas sob a égide do capital, caracterizadas pela estratificação socioeconômica e classista, intensificando as desigualdades sociais pelo agravante das questões interclassistas e raciais. Tanto que na década de 1970 o Movimento Negro Unificado retoma, resignificando, o conceito de raça precisamente como uma construção social forjada nas tensas relações entre brancos, negros e indígenas, demonstrando que o racismo é um fenômeno dinâmico, renovando-se e reestruturando-se mediante as conjunturas históricas e os interesses dos grupos.

Darcy Ribeiro chama nossa atenção para o fato de que a matriz negra é a que mais padeceu e padece em relação ao conflito racial (RIBEIRO, 1995, p. 173), uma vez que ele é intensificado pela questão socioeconômica. Enfatiza o autor: "o maior preconceito entre os brasileiros é o de classe: varia conforme a maior ou menor interação no estilo de vida dos grupos privilegiados. O negro rico, bem sucedido, reconhecido, branqueia-se" (RIBEIRO, 1995, p. 236). Desta forma, desnuda e evidencia as armadilhas do discurso ilusório e falacioso da democracia racial, do respeito à diversidade, já que sem democracia social é impraticável e impossível a democracia racial. Substituir o conceito de raça pelo de etnia não modifica a 
realidade, que é a continuidade do preconceito, dissimulado pela expectativa assimilacionista, que nada mais é do que um racismo encoberto pelo discurso de democracia racial. Mais uma vez, emprestamos as palavras de Darcy Ribeiro, capazes de traduzir o que, de fato, vivemos ainda nos dias de hoje:

prevalece, em todo o Brasil, uma expectativa assimilacionista, que leva os brasileiros a supor e desejar que os negros desapareçam pela branquização progressiva. (...) O aspecto mais perverso do racismo assimilacionista é que ele dá de si uma imagem de maior sociabilidade, quando, de fato, desarma o negro para lutar contra a pobreza que lhe é imposta, e dissimula as condições de terrível violência a que é submetido. É de assinalar, porém, que a ideologia assimilacionista da chamada democracia racial afeta principalmente os intelectuais negros. Conduzindo-os a campanhas de conscientização do negro para a conciliação social e para o combate ao ódio e ao ressentimento do negro. Seu objetivo ilusório é criar condições de convivência em que o negro possa aproveitar as linhas de capilaridade social para ascender, através da adoção explícita das formas de conduta e de etiqueta dos brancos bem-sucedidos. (...) $\mathrm{O}$ assimilacionismo cria uma atmosfera de fluidez nas relações inter-raciais, mas dissuade o negro para sua luta específica, sem compreender que a vitória só é alcançável pela revolução social (...), a democracia racial é possível, mas só é praticável conjuntamente com a democracia social. (RIBEIRO, 1995, p. 224, 226 e 227.)

Polêmica mesmo são as ponderações que faz em relação às contradições do apartheid, muito pertinentes para aqueles que se preocupam em pensar a realidade por contradição, ou seja, dialeticamente, buscando compreender as mediações nem sempre inteligíveis na imediaticidade aparente das circunstâncias e situações vividas cotidianamente. É assim que, pensando por contradição, o autor explicita que o apartheid tem conteúdos de tolerância ignorados pela dita democracia racial assimilacionista que, como vimos, corresponde a uma expectativa de miscigenação falsa, discriminatória, mas dotada de uma força ideologizante e ideologizadora, impulsionando a integração. Cabe aqui a transcrição literal da reflexão desenvolvida pelo autor:

quem afasta o outro e o põe a distância maior possível, admite que ele conserve, lá longe, sua identidade, continuando a ser ele mesmo. Em consequência, induz a profunda solidariedade interna do grupo discriminado, o que o capacita a lutar claramente por seus direitos sem admitir paternalismos (leia-se: assimilacionismos). Nas conjunturas assimilacionistas, ao contrário, se dilui a negritude numa vasta escala de gradações, que quebra a solidariedade, reduz a combatitividade, insinuando a ideia de que a ordem social é uma ordem natural, senão sagrada. (RIBEIRO, 1995, p. 226. Os parênteses são nossos.) 
Sagazmente, Darcy Ribeiro identifica a contradição da quebra de solidariedade do grupo discriminado através da política assimilacionista, sendo ilustrativo o caso dos mulatos, que "participando biológica e socialmente do mundo branco, pode acercar-se melhor de sua cultura erudita, progredindo na medida em que (nega) sua negritude" (RIBEIRO, 1995, p. 223). A positividade dessa contradição, exemplificada pelo apartheid, seria a criação das condições para a mobilização e organização dos negros, possibilitando partirem das justas reivindicações específicas decorrentes do preconceito racial, mas transcendendo-as a partir do momento que através dessa luta e enfrentamento compreendem que a raiz de todos os problemas é a questão classista, socioeconômica, não um determinismo economicista, mas sim uma profunda e abismal desigualdade em relação as condições pressupostas para a produção e reprodução social de suas condições materiais e espirituais de existência enquanto seres humanos.

É assim que recontextualizamos a discussão sobre a questão de gênero, divergindo do modo como é tratada atualmente, entendida como uma categoria de análise relacional, que procura denunciar as desigualdades raciais, classistas, discriminatórias, preconceituosas, de força e poder entre os multiversos mundos do feminino e do masculino. O Movimento das Mulheres, assim como o dos Gays, Lésbicas e Transexuais, têm, todos, suas particularidades e especificidades mais imediatas para reivindicar e lutar, uma questão de justiça e processualidade histórico-social. Todavia, o que há de comum entre todos esses movimentos, e aqueles que lutam por justiça e igualdade social, é o fato de que lutam para que todos independente de classe, sexo, raça, etnia -, enquanto seres sociais - ou seja, seres ontológicos, isto é, que se produziram historicamente como seres humanos através do ato fundante do trabalho, se diferenciando de todas as outras espécies justamente porque criaram o mundo social e o gênero humano, como salienta Lukács (1976-1981), fruto de um processo históricosocial acumulativo, geracional, feito de avanços e recuos, saltos qualitativos, quantitativos e contradições, responsável pela edificação de um patrimônio comum da humanidade, que, apesar de ser comum está impedido de sê-lo devido a apropriação individual e privada da riqueza produzida social e historicamente por essa mesma humanidade - tenham acesso às condições para realização de suas necessidades e potencialidades.

\section{DO POVO-MASSA AO POVO-NAÇÃO - AINDA UMA PROMESSA...}


Quando brotarem as flores/ Quando crescerem as matas/ Quando colherem os frutos/ Digam o gosto pra mim. (Aos Nossos Filhos - Ivan Lins)

Caminhamos para o fechamento do presente artigo, culminando na elucidação da grande proposta e preocupação norteadoras da redação do livro manifesto O Povo Brasileiro, de Darcy Ribeiro, cabendo-nos a tarefa de evidenciar o significado dos dois conceitos essenciais e indubitavelmente imbricados de Povo-Massa e Povo-Nação, contrapondo esse último ao conceito de Estado-Nação, demonstrando suas diferenças irreconciliáveis e substantivas.

Do cunhadismo ao criatório de gente pela miscigenação (fato inédito) entre as matrizes formadoras (índio, negro, europeu), surge um Povo-Novo, mestiço, que busca se fazer, e durante esse árduo e atroz (genocídio, etnocídio, transfiguração étnica) processo de fazimento, faz-se primeiro como Povo-Massa, não no sentido de massa de manobra, leitura que acreditamos crítica da história, mas sim uma "alternidade (que) se organiza na luta por um projeto próprio e alternativo de estruturação social, como ocorreu com os Cabanos, em Canudos, no Contestado e entre os Mucker (...), embora ainda não esteja constituído com uma consciência de etnicidade" (RIBEIRO, 1995, p. 24, 25 e 179).

O Povo-Massa constitui-se de uma maioria mestiça de brasileiros da terra, com condições de vida e trabalho precárias, que vendem sua força de trabalho produzindo mercadorias que geralmente não podem consumir. Formam o contingente que justifica a organização político-administrativa do Estado-Nação que, por sua vez, cria e cultiva os elementos responsáveis pela consolidação da unidade nacional, resultante

\footnotetext{
de um processo continuado e violento de unificação política, logrado mediante um esforço deliberado de supressão de toda identidade étnica discrepante, de repressão e opressão de toda tendência virtualmente separatista. Inclusive de movimentos sociais que aspiravam fundamentalmente edificar uma sociedade mais aberta e solidária. A luta pela unificação potencializa e reforça, nessas condições, a repressão social e classista, castigando como separatistas movimentos que eram meramente republicanos ou antioligárquicos. (RIBEIRO, 1995, p. 23)
}

Daí resulta a Nação brasileira, que impede a realização do verdadeiro Povo-Nação que deve se fazer por brasileiros conscientes de si, de sua unidade e identidade étnica -, já que são educados a introjetar, por inculcação dos bancos escolares, a identidade nacional ditada pelo Estado-Nação, tendo de esquecer para lembrar. Como enfatiza Adelia Ribeiro, "o Brasil, 
nascido da violência da dominação do europeu sobre o índio e o negro há de se lembrar e, também, de se esquecer para lembrar de sua origem, para que possa cotidianamente (re)começar sua narrativa de nação” (MIGLIEVICH-RIBEIRO, 2011, p. 42).

O Povo-Nação precisa se por em transfiguração, tendo por pressuposto a práxis dialética da negação para superação. É necessário refletirmos sobre o contexto histórico-social dos nossos símbolos e signos nacionais, de nossa controversa, complexa, contraditória e não resolvida identidade nacional, desconstruindo-a quando se fizer necessário, a fim de que possamos tomar consciência, de fato, de quem somos. Afinal, não podemos esquecer, conforme alerta Adelia Ribeiro, que a

\begin{abstract}
identidade nacional é um tipo específico de identidade cultural, formada e transformada no âmbito da esfera política que nós chamamos de Estado-Nação. (...) trata-se de perceber as tensões nessa identificação e suspeitar do ambíguo discurso da cultura nacional que se mantém entre tendências regressivas e outras progressivas, mas que jamais se despojam de relações de dominação cultural. (MIGLIEVICH-RIBEIRO, 2011, p. 42)
\end{abstract}

É por isso que "Darcy aposta na nação como campo de luta e de possibilidades transformativas, não apenas no âmbito propriamente da nação, mas das relações com outras nações do mundo" (MIGLIEVICH-RIBEIRO, 2011, p. 29). A reflexão em torno das contradições que marcam a formação da nação e da identidade nacional pode nos auxiliar no processo de autoconstrução, autoconhecimento e reconhecimento do significado de ser parte do gênero humano.

Se o Povo-Nação ainda não se realizou como Povo-Nação é porque ainda não conseguiu transcender sua condição de Povo-Massa, que deve completar a busca do seu em si, se fazendo enquanto classe em si através da (re)construção do seu projeto político-social, com alma social, possibilitando sua mobilização organizativa-mediativa como classe para si, capaz de ir além da luta de classes e das próprias classes, lutando pela criação e acesso as condições para a realização das verdadeiras necessidades, potencialidades e capacidades desse PovoNação, que é o gênero humano, conforme definido anteriormente.

Essas questões tornam clara a oposição entre Estado-Nação e Povo-Nação. O primeiro corresponde a organização de uma estrutura jurídico-política-burocrática para a manutenção e reprodução da ordem social segundo o projeto de desenvolvimento econômico-social liberal/neoliberal capitalista, de caráter conservador-progressista, já que as mudanças são admissíveis, necessárias e planejadas a fim de garantir as condições da acumulação do capital 
e da sua lógica produtiva-social. Já o segundo, na visão de Darcy Ribeiro, compreende a construção da identidade etnicosociocultural, do projeto político-social do povo brasileiro, capaz de se ver, reconhecer e plasmar enquanto parte do gênero humano, lutando pela criação das condições efetivas para sua realização dentro da plenitude possível permitida pelo atual estágio de desenvolvimento das forças produtivas e do patrimônio histórico-social acumulado pela humanidade.

O Povo-Nação é formado, em sua maioria, pela classe marginal, oprimida, composta, como nos informa Darcy Ribeiro, "principalmente (por) negros e mulatos, moradores das favelas e periferias da cidade. Seu desígnio histórico é entrar no sistema, o que sendo impraticável, os situa na condição da classe intrinsecamente oprimida, cuja luta terá de ser a de romper com a estrutura de classes. Desfazer a sociedade para refazê-la" (RIBEIRO, 1995, p. 209). Entretanto, apresenta uma contradição inerente a sua condição de classe, que necessita ser equacionada mediante os embates travados na luta por melhoria das suas condições materiais de existência - essencial e virtualmente educativa, potencializando a conscientização e a politização dos indivíduos sociais envolvidos, uma vez que os capacita para irem além do imediatismo da manutenção e reprodução social, fazendo-os questionar e refletir acerca da edificação e conformação da estrutura social e de sua própria condição de classe, permitindo que se constituam como classe em si e se construam como classe para si -, pois ao mesmo tempo que luta por ingressar no sistema de produção e pelo acesso ao mercado, "só tem perspectiva de integrar a vida social rompendo toda a estrutura de classes, o que faz dela a renovadora da sociedade como combatente da causa de todos os outros explorados e oprimidos" (RIBEIRO, 1995, p. 210).

É assim que entendemos a importância do papel a ser desempenhado pelas classes intermediárias (setores mais dinâmicos) e subalternas (núcleo mais combativo), assim denominadas por Darcy Ribeiro ${ }^{2}$, no processo de mobilização e organização combativaofensiva da classe majoritária, oprimida e marginal, fortalecendo-a no enfrentamento aos donos do poder e da propriedade indevidamente privatizada dos bens e meios de produção sociais, já que podem atuar como mediadores do acesso daquela classe ao patrimônio histórico-cultural acumulado pela humanidade, justamente por estarem inseridos diretamente no sistema de produção e mercado, integrados a dinâmica da sociabilidade capitalista, cujas contradições são potencialmente capazes de contribuir para reapropriação e reelaboração das ideias dominantes difundidas, desconstruindo-as e reconstruindo-as para ir além da estrutura de classes, transcendendo positivamente o modo de produção capitalista através da edificação 
de um novo modo de vida e de relações sociais e de produção que contribuam para a realização do gênero humano.

A reflexão desenvolvida por Adelia Ribeiro ratifica o exposto. Segundo a autora:

a capacidade de um povo interpretar a sua própria situação é instrumento simbólico para sua atuação na história, pela organização e valores e interesses comuns (concatenados e traduzidos pela elaboração de um projeto político-social, com alma social). Ainda quando vêm dos estratos dominantes os parâmetros de normatização da sociedade, não há que se subestimar os estratos subordinados em sua competência para recepcionar e reelaborar as ideias produzidas (circularidade cultural, defendida por Carlo Ginzburg). Antes, a recepção pode implicar uma forma de transgressão. Daí que o pensamento social contém um gérmen de criatividade social de consequências férteis a se desenvolver ou não, capaz de atuar no incremento de uma cosmovisão capaz de se opor ao status quo. (MIGLIEVICHRIBEIRO, 2011, p. 26. Os parênteses são nossos.)

É por isso que para Darcy Ribeiro, "a constituição do povo brasileiro na superação da ninguendade ainda não se deu, exceto como promessa” (RIBEIRO, 1995, p. 42). Todavia, ela pode vir a se tornar realidade se as condições objetivas então existentes forem percebidas, elaboradas, trabalhadas e desenvolvidas pelo Povo-Massa em sua autoconstrução e autodeterminação como Povo-Nação, no sentido darcyniano explicitado, dando a resposta ao grande desafio que o Brasil enfrenta, que é, segundo Darcy, “alcançar a necessária lucidez para concatenar as energias desse Povo-Nação oprimido e orientá-la politicamente, com clara consciência dos riscos de retrocesso e das possibilidades de liberação que elas ensejam". (RIBEIRO, 1995, p. 25) Afinal,

\begin{abstract}
ao contrário do que alega a historiografia oficial, nunca faltou aqui, até excedeu, o apelo à violência pela classe dominante como arma fundamental da construção da história. O que faltou, sempre, foi espaço para movimentos sociais capazes de promover sua reversão. Faltou sempre, e falta ainda, clamorosamente, uma clara compreensão da história vivida, como necessária nas circunstâncias em que ocorreu, e um claro projeto alternativo de ordenação social, lucidamente formulado, que seja apoiado e adotado como seu pelas grandes maiorias. (RIBEIRO, 1995, p. 26)
\end{abstract}

Uma revolução político-social, de alma social, pressupõe, como diria Lênin (1979) uma "situação revolucionária", embora nem toda situação revolucionária conduza a uma revolução. São "os riscos de retrocesso e das possibilidades de liberação", mencionados por Darcy Ribeiro. O que caracteriza uma "situação revolucionária"? No entendimento de Lênin, são três pontos principais: 
1) impossibilidade para as classes dominantes manterem sua dominação de forma inalterada; crise da 'cúpula', crise da política da classe dominante, o que cria uma fissura através da qual o descontentamento e a indignação das classes oprimidas abrem caminho. Para que a revolução estoure não basta, normalmente, que 'a base não queira mais' viver como outrora, mas é necessário ainda que 'a cúpula não o possa mais’; 2) agravamento, além do comum, da miséria e da angústia das classes oprimidas; 3) desenvolvimento acentuado, em virtude das razões indicadas acima, da atividade das massas, que se deixam, nos períodos 'pacíficos', saquear tranquilamente, mas que, em períodos agitados, são empurradas tanto pela crise no seu conjunto como pela própria 'cúpula', para uma ação histórica independente. Sem essas alterações objetivas, independentes não somente da vontade desses ou daqueles grupos e partidos, mas também dessas ou daquelas classes, a revolução é, como regra geral, impossível. É o conjunto dessas alterações objetivas que constitui uma situação revolucionária. (...) a revolução não surge em toda situação revolucionária, mas somente nos casos em que a todas alterações objetivas acima enumeradas vem juntar-se uma alteração subjetiva, a saber: a capacidade, no que respeita à classe revolucionária, de conduzir ações revolucionárias de massa suficientemente vigorosas para quebrar completamente (ou parcialmente) o antigo governo, que não 'cairá' jamais, mesmo em época de crise, sem 'ser derrubado'. (LÊNIN, 1979, p. 27 e 28.)

Qual a situação das condições objetivas vivenciadas por nós? Potencializam e abrem brechas para a conformação de uma "situação revolucionária"? Os movimentos sociais necessitam realizar essa avaliação e reflexão histórica-social, a fim de produzir as acelerações históricas ${ }^{3}$ necessárias à realização da transcendência positiva para a construção de uma nova sociabilidade humana, onde os indivíduos possam, efetivamente, reconhecerem-se e enxergarem-se enquanto parte do gênero humano, defendendo a igualdade das oportunidades e acesso ao patrimônio histórico-social acumulado pela humanidade e as riquezas socialmente produzidas. Porém, é necessário estarmos cônscios de que não há fórmulas, receitas, muito menos milagres e mágicas, muitas gerações terão de perecer para que outras venham a prosperar. Talvez, jamais saberemos o gosto do fruto, como nos alerta Ivan Lins através da epígrafe destacada de sua canção: Aos Nossos Filhos, transcrita no início do item que viemos trabalhando. A imediaticidade, o utilitarismo pragmático, o hedonismo egoístico que marca o modo de ser dos indivíduos sociais na sociabilidade capitalista não nos servem como parâmetros éticos e morais nessa nova forma de sociabilidade humana a ser estruturada. Alguém terá de nos dizer o gosto desse fruto.

Acreditamos que Darcy Ribeiro tinha essa sapiência, tanto que no último parágrafo da introdução de $O$ Povo Brasileiro diz: "este livro é um esforço para contribuir ao atendimento desse reclamo de lucidez (da compreensão da história vivida)" (RIBEIRO, 1995, p. 26. O parênteses é nosso). Através dessa obra deixa sua contribuição ao gênero humano em seu permanente processo de fazimento dialético, de autoconstrução e autodeterminação, daí ter tido o cuidado de esclarecer aos leitores, ao prefaciá-la, que se tratava de um livro "que quer 
ser participante, que aspira a influir sobre as pessoas, que aspira a ajudar o Brasil a encontrarse a si mesmo" (RIBEIRO, 1995, p. 17).

Ainda estamos tentando cumprir essa tarefa histórica, inacabada, oprimida, reprimida e tantas vezes abortada pela violência atroz e descomunal da classe que personifica, encarna e produz as condições para a reprodução e garantia de perpetuação do capital e da sociabilidade capitalista. Contudo, essa luta se fortalecerá a medida que formos nos reapropriando, lúcida e conscientemente, de nossa história vivida, reescrevendo-a, redirecionando-a, revitalizando-a e resignificando o patrimônio material e espiritual histórica e socialmente edificado pela humanidade, compreendendo o verdadeiro significado do que seja ser parte do gênero humano, articulando e organizando todas as lutas e movimentos sociais, com suas reivindicações justas e específicas à questão de raiz essencial e genérica, que é a realização da autodeterminação humana e da justiça, igualdade e democracia social para toda humanidade.

\section{REFERÊNCIAS}

ANDERSON, Perry. "Balanço do Neoliberalismo". In: SADER, Emir; GENTILI, Pablo. (Orgs.) Pós-neoliberalismo: as políticas sociais e o Estado democrático. Rio de Janeiro: Paz e Terra, 1998.

DAMIANI, Cassia. "Neoliberalismo, Educação e Luta de Classes no Brasil: Breve Análise". In: NETO, Enéas Arrais; OLIVEIRA, Elenilce Gomes; VASCONCELOS, José Gerardo. (Orgs.) Mundo do Trabalho - Debates Contemporâneos. Fortaleza: Editora UFC, 2004.

FRIGOTTO, Gaudêncio. "Escola Pública Brasileira na atualidade: lições da história". In: LOMBARDI, José Claudinei; SAVIANI, Dermeval; NASCIMENTO, Maria Isabel Moura. (Orgs.) A Escola Pública no Brasil - História e Historiografia. Campinas, SP: Autores Associados: HISTEDBR. (Coleção Memória e Educação). 2005.

GINZBURG, Carlo. O Queijo e Os Vermes - O cotidiano e as ideias de um moleiro perseguido pela Inquisição. Tradução Maria Betânia Amoroso. São Paulo: Companhia das Letras, 1987. 
LENIN, Vladimir I. A falência da II Internacional. Trad. Armando Boito Júnior e Maria Luiza Gonçalves. $1^{\mathrm{a}}$ ed. São Paulo: Kairós Livraria e Editora Ltda. (Série Materialismo Histórico), 1979.

LÉVILLAN, Philippe. “Os protagonistas: da biografia”. In: REMOND, René (org.). Por uma história política. $2^{\mathrm{a}}$ ed. Rio de Janeiro: FGV,2003.

LUKÁCS, Georg. (1976-1981) Ontologia dell'Essere Sociale. 3v. Roma: Riuniti.

MCLAREN, Peter. "Fúria e esperança: a pedagogia revolucionária de Peter McLaren Entrevista com Peter McLaren”. Currículo sem Fronteiras, v.1, n.2, p. 171-188. 2001.

MIGLIEVICH-RIBEIRO, Adelia Maria. "Darcy Ribeiro e o enigma Brasil: um exercício de descolonização epistemológica”. Sociedade e Estado (UnB. Impresso), v. 26, p. 23-49. 2011.

PILETTI, Nelson. História do Brasil. São Paulo: Ed. Ática. 1992.

RIBEIRO, Darcy. O Povo Brasileiro - A Formação e o Sentido do Brasil. Rio de Janeiro: Civilização Brasileira.

SILVA-SANTOS, Diego Júnior da Silva (et. al.) "Raça Versus Etnia - diferenciar para melhor aplicar". Revista Dental Press de Ortodontia e Ortopedia Facial (Impresso), v. 15, p. 121-124, 2011.

TONET, Ivo. As tarefas dos intelectuais, hoje. 1998. Disponível em: http://www.ivotonet.xpg.com.br, [consultado em: 23/08/2012].

\footnotetext{
${ }^{1}$ Professora da Universidade Federal do Piauí. Mestre em Ciências Sociais pela UNESP-Marília/SP. Depto de Ciências Humanas e Educação. Pesquisadora do LABOR, UFC/CE. Coordenadora do Projeto de Pesquisa GEMPI, da UFPI/Picos. E-mail: iaeldeo@ gmail.com

${ }^{2}$ Ver O Povo Brasileiro, Darcy Ribeiro, páginas 176-179 e 208-212.

${ }^{3}$ Aceleração difere de atualização histórica. Conforme Darcy Ribeiro, a atualização é a inserção subordinada "de povos atrasados em formações socioculturais estruturadas e em sistemas tecnologicamente superiores, 
implicando em efetiva perda de autonomia ou em sua destruição como entidade étnica" (RIBEIRO, 1995, p. 35). Já a aceleração é a "possibilidade de desenvolvimento autônomo, uma superação do atraso que não se dá pela modernização reflexa ou conservadora. Trata-se da mobilização de fatores endógenos e/ou exógenos, tanto faz, pela criatividade e conhecimento da própria sociedade que avista o desenvolvimento" (MIGLIEVICHRIBEIRO, 2011, p. 35). É importante destacarmos que a incorporação/integração, na visão do autor de O Povo Brasileiro, difere de assimilação, pois é mantida a especificidade dentro da generalização. Daí a atualização ser a "perda de autonomia étnica dos núcleos engajados, sua dominação e transfiguração, estabelecendo as bases sobre as quais se edificaria daí em diante a sociedade brasileira" (RIBEIRO, 1995, p. 74). Portanto, subserviência inserida ao estágio de evolução daquele que se impõe e domina.

RECEBIDO EM: Abril de 2016

APROVADO EM: Junho de 2016 